H. Khorsandi ${ }^{1}$, A. Mohammadi ${ }^{1}$, F. Kariminejad ${ }^{2}$, M. Haghighi ${ }^{3}$, S. Karimzadeh ${ }^{1}$, J. Khorsandi ${ }^{4}$, A.A. Aghapour ${ }^{1}$

\title{
OPTIMIZING LINEAR ALKYL BENZENE SULFONATE REMOVAL USING FENTON OXIDATION PROCESS IN TAGUCHI METHOD
}

\author{
${ }^{1}$ Urmia University of Medical Sciences, Urmia, Iran; \\ ${ }^{2}$ Mazandaran University of Medical Sciences, Sari, Iran; \\ ${ }^{3}$ Kashan University of Medical Sciences, Kashan, Iran; \\ ${ }^{4}$ Azarbaijan Shahid Madani University, Tabriz, Iran \\ hassankhorsandi@yahoo.com
}

Linear alkyl benzene sulfonate (LAS), which is the most common used anionic surfactant in detergents manufacturing, can discharge onto water resources through wastewater and causes change in taste and odor, disruption in water treatment processes, aquatics death, and oxygen transfer limitation. Accordingly, this article investigates to optimize LAS removal using Fenton oxidation process in Taguchi Method for the first time. LAS removal using Fenton oxidation was perused experimentally in a lab-scale reactor. In order to save relevant costs, 25 runs were qualified to specify the optimum conditions of Fenton oxidation using Taguchi method by Minitab 16 software. Sampling and testing procedures were executed based on the standard methods for the examination of water and wastewater. The optimum conditions included $900 \mathrm{mg} / \mathrm{L}$ hydrogen peroxide, $170 \mathrm{mg} / \mathrm{L}$ ferrous ion, $\mathrm{pH}$ of 4 and the reaction time of $20 \mathrm{~min}$. Fenton oxidation, as a second order reaction with the rate coefficient of $0.0152 \mathrm{~L} / \mathrm{mg} \cdot \mathrm{min}$, provided $86.5 \%$ efficiency for LAS removal in the optimum conditions. Despite Fenton oxidation appeared as a high efficiency process in LAS removal, low removal efficiency of chemical oxygen demand corresponding with LAS affirmed its partial degradation.

Keywords: linear alkyl benzene sulfonate, detergent, Fenton oxidation, wastewater.

\section{Introduction}

Surface active agents, usually referred to as surfactants, are amphipathic molecules that consist of a non-polar hydrophobic portion, usually a straight or branched hydrocarbon chain containing $8-18$ carbon atoms, which is attached

(C) H. Khorsandi, A. Mohammadi, F. Kariminejad, M. Haghighi, S. Karimzadeh,

J. Khorsandi, A.A. Aghapour, 2016 486

ISSN 0204-3556. Химия и технология воды, 2016, m.38, №5 
to a polar hydrophilic portion. Hence, they are able to solve insoluble materials and are used as one of the main ingredients in the structure of detergents [1, 2]. So that, in 2006, the worldwide production of detergents has been announced over 12.5 million tonnes. Linear alkyl benzene sulfonate (LAS) anionic surfactant makes up approximately $5-30 \%$ by weight of various detergents because of its biodegradability [1, 3, 4].

Because surfactants produce stable foams at the surface of receiving waters in more than $1 \mathrm{mg} / \mathrm{L}$ [2], they can cause changes in taste and odor, disruptions in water treatment processes, aquatics death, and oxygen transfer limitation $[1,3-5]$.

In addition to domestic wastewater, the main sources of surfactants in water resources comprise wastewater resulting from industries producing detergents, cleaners, cosmetics, and textile, as well as cleaning operations in various industries [1 - 3]. LAS concentration in raw municipal wastewater ranges from 3 to $21 \mathrm{mg} / \mathrm{L} \mathrm{[5]}$.

According to standards provided by the Iran department of environment, the maximum allowable concentration of detergent in the effluent for discharge to surface waters and absorbing wells or agricultural reuse is 1.5 and $0.5 \mathrm{mg} / \mathrm{L}$, respectively [6].

So far, various approaches such as coagulation, floatation, biological processes, adsorption, membrane processes, ultrasonic irradiation and advanced oxidation have been studied to remove detergents from wastewaters [3 - 5, $7-14]$.

Oxidation processes have been investigated for the pre-treatment of refractory surfactants in the past decades. Results of these studies reveal that surfactants resistant to biological treatment are removed well by ozonation and photochemical methods [1, 3, 15-21].

Fenton is one of the oxidation processes in which ferrous ion as a catalyst reacts in an acidic condition with hydrogen peroxide as oxidizer and produces hydroxyl radical. This process has great potential for oxidation of refractory organic compounds due to producing highly active hydroxyl radicals [15,16,22]. Fenton oxidation is affordable while having optimal performance and easy operation in comparison with other advanced oxidation processes [8 - 11].

Lin S.H. et al. [9] showed that the efficiency of Fenton oxidation process in removing $\mathrm{ABS}$ and LAS enhances if it is integrated with the coagulation process.

Wang X.J. et al. [11] reduced LAS amount in detergent factory wastewater to less than $5 \mathrm{mg} / \mathrm{L}$ using pretreatment by Fenton oxidation and biological processes. 
Mousavi S.A.R. et al. [8] acquired Fenton oxidation process efficiency about $86 \%$ to remove $470 \mathrm{mg} / \mathrm{L}$ LAS while the removal efficiency of chemical oxygen demand (COD) corresponding to LAS was obtained approximately $60 \%$. The process included $750 \mathrm{mg} / \mathrm{L}$ hydrogen peroxide, $130 \mathrm{mg} / \mathrm{L}$ ferrous ion, $\mathrm{pH}$ about 3 , and reaction time of $80 \mathrm{~min}$.

Abdel-Rahman A.M. et al. [5] reported the LAS removal efficiency by wastewater stabilization ponds between 55 and $77 \%$ in various seasons.

Although some studies have been conducted concerning the efficiency of Fenton oxidation for treatment of industrial wastewaters, Taguchi method has not yet been used for determining the optimal conditions of this process to remove the anionic detergents. Therefore, this article investigates optimizing LAS removal using Fenton oxidation process in Taguchi method for the first time in order to reduce costs.

\section{Experimental}

Fenton oxidation was performed experimentally in a lab-scale $500 \mathrm{ml}$ batch reactor. In order to provide the study objectives, residual LAS and COD concentrations as dependent variables were analyzed versus operational parameters such as initial concentration of LAS $(8-40 \mathrm{mg} / \mathrm{L})$, initial COD $(100-$ $700 \mathrm{mg} / \mathrm{L})$, hydrogen peroxide $(80-1200 \mathrm{mg} / \mathrm{L})$, ferrous ion $(30-170 \mathrm{mg} / \mathrm{L})$, $\mathrm{pH}(4$ to 8$)$ and time reaction (20 to $60 \mathrm{~min})$ as independent variables. The range of investigated parameters has been chosen based on the characteristic of municipal wastewater and the experiences obtained from the previous studies concerning Fenton oxidation.

Synthetic solutions were prepared by LAS ("Acros Organic", USA), $\mathrm{C}_{18} \mathrm{H}_{29} \mathrm{NaO}_{3} \mathrm{~S}$. Sampling and testing procedures were accomplished using the standard methods for the examination of water and wastewater. LAS was examined using $5540 \mathrm{C}$ standard method [23, 24] in which methylene blue active substances (MBAS) bring about the transfer of methylene blue, a cationic dye, from an aqueous solution into an immiscible organic liquid upon equilibration. The intensity of the resulting blue color in the organic phase is a measure of MBAS. It comprises three successive extractions from acid aqueous medium containing excess methylene blue into chloroform $\left(\mathrm{CHCl}_{3}\right)$, followed by an aqueous backwash and measurement of the blue color in the $\mathrm{CHCl}_{3}$ by spectrophotometry at $652 \mathrm{~nm}$.

COD experiments or oxygen consumed for oxidation of LAS were analyzed by closed reflux-colorimetric method, $5220 \mathrm{D}$ standard method [23, 25, 26]. 
In this approach, a sample is refluxed in strongly acid solution with a known excess of potassium dichromate $\left(\mathrm{K}_{2} \mathrm{Cr}_{2} \mathrm{O}_{7}\right)$ as an oxidant. This results in the change of chromium from the hexavalent (VI) state to the trivalent (III) state. $\mathrm{Cr}_{2} \mathrm{O}_{7}{ }^{2-}$ and $\mathrm{Cr}^{3+}$ are colored and absorb strongly 420 and $600 \mathrm{~nm}$ spectrums, respectively [23].

Hydrogen peroxide interferes in COD amount and increases illusively it. To thwart the intervention of hydrogen peroxide, before measuring COD, samples' $\mathrm{pH}$ was adjusted within the range of $7-8$ [27].

In order to save costs, experiments were qualified by the Taguchi method [28] using Minitab 16 software. In this software, $\mathrm{pH}$, initial LAS concentration, $\mathrm{Fe}^{2+}$ and $\mathrm{H}_{2} \mathrm{O}_{2}$ concentrations, and the reaction time were selected in five levels. Therefore, 25 specific runs were examined according to Table 1.

Table 1. LAS and COD removal efficiency by Fenton oxidation

\begin{tabular}{|c|c|c|c|c|c|c|c|c|c|}
\hline \multirow{2}{*}{$\mathrm{pH}$} & $\mathrm{H}_{2} \mathrm{O}_{2}$ & $\mathrm{Fe}^{2+}$ & \multirow{2}{*}{$\begin{array}{c}\text { Time, } \\
\text { min }\end{array}$} & \multicolumn{2}{|c|}{ LAS mg/L } & \multicolumn{2}{|c|}{$\mathrm{COD}, \mathrm{mg} / \mathrm{L}$} & LAS & COD \\
\hline & \multicolumn{2}{|c|}{$\mathrm{mg} / \mathrm{L}$} & & Initial & Effluent & Initial & Effluent & \multicolumn{2}{|c|}{ rem. $\%$} \\
\hline 4 & 80 & 30 & 20 & 8 & 2.5 & 124.95 & 102.06 & 68.75 & 18.32 \\
\hline 4 & 300 & 80 & 30 & 10 & 2.9 & 193.62 & 106.64 & 71.00 & 42.86 \\
\hline 4 & 600 & 120 & 40 & 15 & 2.4 & 296.62 & 156.42 & 84.00 & 47.27 \\
\hline 4 & 900 & 140 & 50 & 25 & 2.8 & 405.35 & 250.84 & 88.80 & 38.12 \\
\hline 4 & 1200 & 170 & 60 & 40 & 3.4 & 482.60 & 165.00 & 91.50 & 65.81 \\
\hline 5 & 80 & 80 & 40 & 25 & 4.4 & 139.25 & 90.61 & 82.40 & 34.13 \\
\hline 5 & 300 & 120 & 50 & 40 & 6.9 & 282.31 & 187.89 & 82.75 & 33.44 \\
\hline 5 & 600 & 140 & 60 & 8 & 3.3 & 305.20 & 189.17 & 58.75 & 40.31 \\
\hline 5 & 900 & 170 & 20 & 10 & 2.3 & 382.46 & 279.45 & 77.00 & 26.93 \\
\hline 5 & 1200 & 30 & 30 & 15 & 7.6 & 534.10 & 173.59 & 49.33 & 67.5 \\
\hline 6 & 80 & 120 & 60 & 10 & 4.6 & 107.88 & 62.00 & 54.00 & 42.47 \\
\hline 6 & 300 & 140 & 20 & 15 & 4.1 & 230.81 & 139.35 & 82.67 & 39.67 \\
\hline 6 & 600 & 170 & 30 & 25 & 4.8 & 368.15 & 242.26 & 80.80 & 34.20 \\
\hline 6 & 900 & 30 & 60 & 40 & 6.0 & 519.79 & 465.43 & 85.00 & 10.46 \\
\hline 6 & 1200 & 80 & 20 & 8 & 3.3 & 671.44 & 399.62 & 58.75 & 40.48 \\
\hline 7 & 80 & 140 & 30 & 40 & 19.2 & 156.42 & 93.47 & 52.00 & 40.24 \\
\hline 7 & 300 & 170 & 40 & 8 & 4.2 & 222.23 & 107.178 & 47.50 & 51.5 \\
\hline 7 & 600 & 30 & 50 & 10 & 7.0 & 376.73 & 310.93 & 30.00 & 17.47 \\
\hline 7 & 900 & 80 & 60 & 15 & 3.1 & 419.65 & 245.12 & 33.79 & 41.59 \\
\hline 7 & 1200 & 120 & 20 & 25 & 5.1 & 491.18 & 362.43 & 79.60 & 26.21 \\
\hline 8 & 80 & 170 & 50 & 15 & 5.8 & 222.23 & 367.87 & 61.33 & 24.46 \\
\hline 8 & 300 & 30 & 60 & 25 & 11.2 & 296.62 & 222.23 & 55.20 & 25.08 \\
\hline
\end{tabular}


Table 1 (Cont.)

\begin{tabular}{|c|c|c|c|c|c|c|c|c|c|}
\hline 8 & 600 & 80 & 20 & 40 & 17.1 & 299.48 & 247.98 & 57.25 & 17.20 \\
\hline 8 & 900 & 120 & 30 & 8 & 3.8 & 282.31 & 202.20 & 52.50 & 28.38 \\
\hline 8 & 1200 & 140 & 40 & 10 & 4.8 & 496.90 & 419.68 & 52.00 & 15.55 \\
\hline
\end{tabular}

The signal to noise ratio as an optimal condition index was applied based on following equation [28] to determine the effect of independent variables and eventually to introduce the optimal conditions and prioritizing them in LAS removal:

$$
\frac{\mathrm{S}}{\mathrm{N}}=-10\left(\log \sum \frac{\frac{1}{\left(y_{i}^{2}\right)}}{n}\right),
$$

where $n$ is the number of tests and $y_{i}$ is the response value measured for each test (percent of LAS removal); in this formula, the bigger $\mathrm{S} / \mathrm{N}$ ratio the better condition [28].

The Kruskal-Wallis nonparametric one-way analysis of variance was applied using SPSS 16 software for comparing the results of Fenton oxidation runs in LAS removal.

\section{Results and discussion}

To achieve optimal conditions of Fenton oxidation process, LAS removal efficiency was determined at 25 runs specified using Taguchi method that corresponding results are presented in Table 1.

The amount of $\mathrm{S} / \mathrm{N}$ ratio for factors affecting LAS removal is shown in Fig. 1. According to the principals of Taguchi method, the highest $\mathrm{S} / \mathrm{N}$ ratio indicates the optimal level of each factor. Accordingly, the optimal conditions to remove $25 \mathrm{mg} / \mathrm{L}$ LAS using Fenton oxidation include $\mathrm{pH}$ of 4, $900 \mathrm{mg} / \mathrm{L}$ hydrogen peroxide, $170 \mathrm{mg} / \mathrm{L}$ ferrous ion and time of $20 \mathrm{~min}$. The average LAS removal efficiency reached $86.5 \%$ upon laboratory results in optimal conditions; however, the removal efficiency of COD corresponding to LAS was $30 \%$. On this basis, COD corresponding to LAS was decreased from 350 to $245 \mathrm{mg} / \mathrm{L}$ by Fenton oxidation in the optimal conditions. 


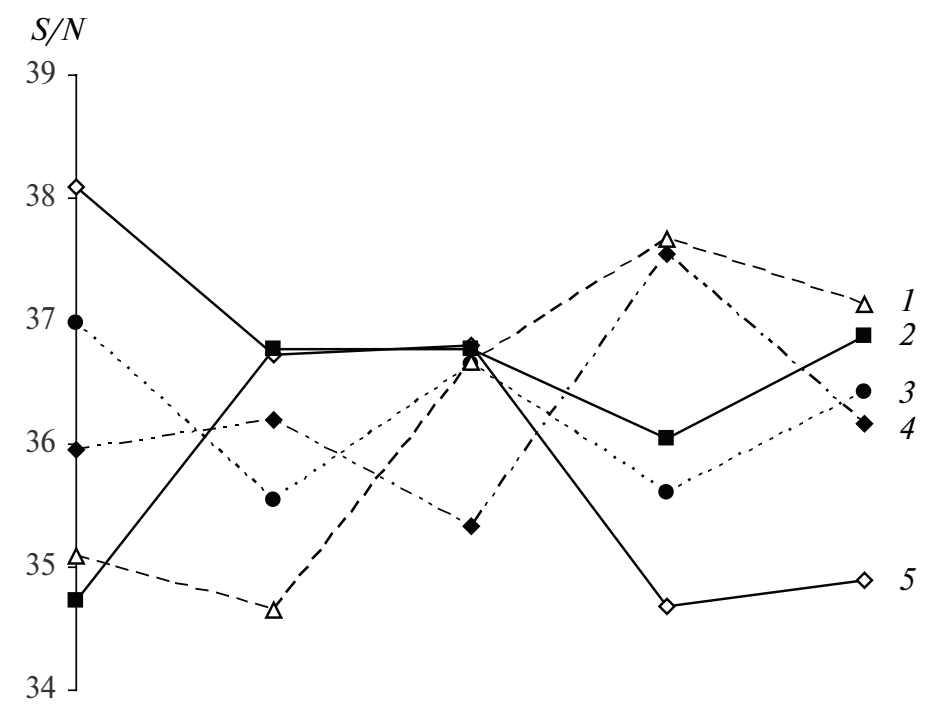

Fig. 1. S/N ratio versus levels of parameters affecting LAS removal: 1 - initial LAS concentration (8; 10; 15; 25; $50 \mathrm{mg} / \mathrm{L}) ; 2$ - ferrous ion (30, 80, 120, $140,170 \mathrm{mg} / \mathrm{L})$; 3 - time (20 - $60 \mathrm{~min}) ; 4$ - hydrogen peroxide (80; 300; 600; 900; $1200 \mathrm{mg} / \mathrm{L}$ ); $5-p H(4-8)$.

After conducting experiments according to Taguchi method, in addition to determine the optimal value of parameter affecting LAS removal, the importance of independent variables was prioritized to introduce optimal conditions in accordance with Table 2 . In this table, $\Delta$ is the difference between the maximum and minimum values of $\mathrm{S} / \mathrm{N}$ ratio, and the paramount parameter in LAS removal entails the $\Delta_{\max }$.

The Kruskal-Wallis nonparametric one-way analysis of variance test demonstrated the significant difference within 25 runs efficiencies on LAS removal by Fenton oxidation $(p<0.05)$.

The study of residual LAS concentration, logarithmic concentration and inverse concentration versus time in the optimal conditions based on the Fig. 2 indicated that Fenton oxidation for LAS removal is a second order reaction with the rate coefficient of $0.0152 \mathrm{~L} / \mathrm{mg} \cdot \min$.

Although the maximum LAS removal efficiency of Fenton oxidation, 91\%, was achieved by $1200 \mathrm{mg} / \mathrm{L}$ hydrogen peroxide, $170 \mathrm{mg} / \mathrm{L}$ ferrous ion, $\mathrm{pH}$ of 4 and the time of 60 min based on Table 1; the optimal conditions was introduced by Minitab 16 software in view of LAS removal efficiency and chemical requirements at $900 \mathrm{mg} / \mathrm{L}$ hydrogen peroxide, ferrous ion $170 \mathrm{mg} / \mathrm{L}, \mathrm{pH}$ of 4, and 20 min according to Fig.1 and Table 2. 


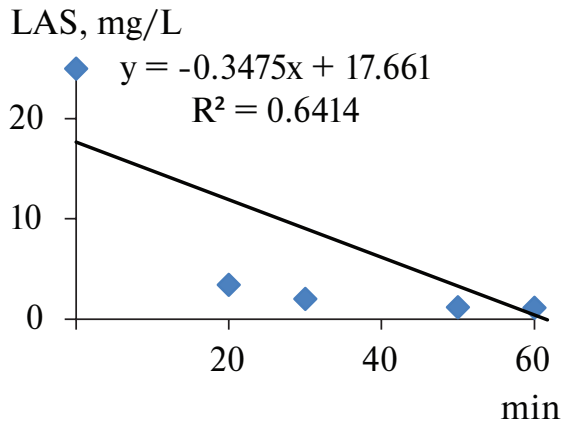

$\ln$ LAS

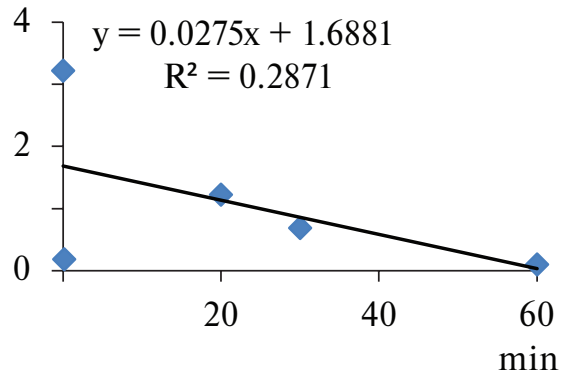

$1 /$ LAS

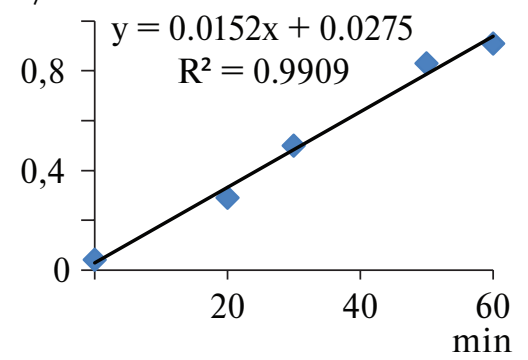

Fig. 2. Reaction order of Fenton oxidation: variation of residual LAS concentration (a), logarithmic concentration (b) and inverse concentration (c) versus time in the optimal conditions.

Table 2. The priority of independent variables to introduce optimal conditions

\begin{tabular}{|c|c|c|c|c|c|}
\hline \multirow{2}{*}{ Level } & \multicolumn{5}{|c|}{$\mathrm{S} / \mathrm{N}$} \\
\cline { 2 - 6 } & $\mathrm{pH}$ & $\mathrm{H}_{2} \mathrm{O}_{2}$ & $\mathrm{Fe}^{2+}$ & Time & LAS \\
\hline 1 & 38.09 & 35.96 & 34.72 & 36.98 & 35.09 \\
\hline 2 & 36.73 & 36.20 & 36.77 & 35.55 & 34.65 \\
\hline 3 & 36.80 & 35.34 & 36.78 & 36.65 & 36.66 \\
\hline 4 & 34.68 & 37.54 & 36.04 & 35.6 & 37.66 \\
\hline 5 & 34.89 & 36.16 & 36.88 & 36.42 & 37.13 \\
\hline$\Delta$ & 3.41 & 2.19 & 2.16 & 1.42 & 3.01 \\
\hline
\end{tabular}

The required time for Fenton oxidation depends on the catalyst, oxidant, and pollutant concentrations according to the results in Table 1; however, no significant difference in LAS removal efficiency was observed by increasing time in the optimal conditions ( $p<0.05$ ) with regard to Fig. 2, $a$ which is consistent with Mohd Ariffin A.H. et al. findings [10]. 
In Fenton oxidation process, organic carbon is transformed into inorganic carbon such as carbon dioxide. In longer reaction times, carbon dioxide will be transformed into bicarbonate and carbonate according to reactions (1) and (2). These intermediate products act as a scavenger of the hydroxyl radical according to reactions (3) and (4). Hence, they can reduce LAS oxidation by consuming hydroxyl radical [29]:

$$
\begin{aligned}
& \mathrm{CO}_{2}+\mathrm{H}_{2} \mathrm{O} \leftrightarrow \mathrm{H}_{2} \mathrm{CO}_{3} \leftrightarrow \mathrm{H}^{+}+\mathrm{HCO}_{3}^{-} \\
& \mathrm{HCO}_{3}^{-} \leftrightarrow \mathrm{H}^{+}+\mathrm{CO}_{3}^{2-} \\
& \mathrm{OH}^{-}+\mathrm{HCO}_{3}^{-} \leftrightarrow \mathrm{H}_{2} \mathrm{O}+\mathrm{CO}_{3}^{-} \\
& \mathrm{OH}^{+}+\mathrm{CO}_{3}^{2-} \leftrightarrow \mathrm{OH}^{-}+{ }^{-} \mathrm{CO}_{3}^{-}
\end{aligned}
$$

According to Table 1, $\mathrm{Fe}^{2+} / \mathrm{H}_{2} \mathrm{O}_{2}$ ratio is considered as one of the factors affecting the efficiency of Fenton process in removing LAS. In optimal conditions, $\mathrm{Fe}^{2+} / \mathrm{H}_{2} \mathrm{O}_{2}$ ratio of 0.08 was introduced by Minitab 16 software for the removal of LAS. In various studies, depending on the type of pollutant, this ratio has been announced between 0.04 and 0.12 . Based on reaction (5), $\mathrm{Fe}^{2+}$ alongside $\mathrm{H}_{2} \mathrm{O}_{2}$ in an appropriate molar ratio increases the production of hydroxyl radical and decreases the pollutants. However, the increase in molar ratio of $\mathrm{Fe}^{2+} / \mathrm{H}_{2} \mathrm{O}_{2}$ and the excessive presence of ferrous ions decreases the efficiency of Fenton oxidation through the unnecessary consumption of hydroxyl radical according to reaction (6) [29, 30]:

$$
\begin{aligned}
& \mathrm{Fe}^{2+}+\mathrm{H}_{2} \mathrm{O}_{2} \rightarrow \mathrm{Fe}^{3+}+\mathrm{OH}^{\cdot}+\mathrm{OH}^{-} \\
& \mathrm{Fe}^{2+}+\mathrm{OH}^{\cdot} \rightarrow \mathrm{Fe}^{3+}+\mathrm{OH}^{-}
\end{aligned}
$$

Since ferrous ion is more soluble in a $\mathrm{pH}$ of about 3 to 4 , the production of hydroxyl radical will increase by the reaction between ferrous ion and hydrogen peroxide in an acidic $\mathrm{pH}$. On the other hand, alkaline $\mathrm{pH}$ will lead to the formation of the Ferric hydrate and the rapid decomposition of $\mathrm{H}_{2} \mathrm{O}_{2}$ to oxygen and water, thus limiting the production of $\mathrm{OH}^{*}$ radical $[8,10,31]$. Therefore, the efficiency of Fenton oxidation process in removing LAS increases in an acidic $\mathrm{pH}$. The results presented in Table 1 completely correspond with this analytical description. After LAS oxidation, $\mathrm{pH}$ is reduced due to the production of organic acids [8].

Ahmadi M. et al. [30] obtained the maximum removal of sodium dodecylbenzene sulfonate using Fenton oxidation in $\mathrm{pH}$ of 3.77 that it is near to our results. 
Lin S.H. et al. [9] introduced the appropriate conditions of Fenton oxidation process at $90 \mathrm{mg} / \mathrm{L}$ ferrous ion, $60 \mathrm{mg} / \mathrm{L}$ hydrogen peroxide, the time of $50 \mathrm{~min}$, and initial $\mathrm{pH}$ of 3 . Under these conditions, LAS and ABS removal efficiencies were reported 93.21 and $93.4 \%$ in the absence of coagulation and 98.4 and $99.5 \%$ in the presence of coagulation, respectively. This study proved the positive effect of coagulation for improving LAS removal efficiency, which is justifiable with detergents adsorption on chemical flocs.

Wang X.J. et al. [11] decreased LAS of the detergent factory wastewater from 490 to $23 \mathrm{mg} / \mathrm{L}$ through Fenton oxidation $(120 \mathrm{mg} / \mathrm{L}$ hydrogen peroxide, $600 \mathrm{mg} / \mathrm{L}$ ferrous ion, $\mathrm{pH}$ of 8 and the reaction time of $40 \mathrm{~min}$ ), and then detracted it to less than $5 \mathrm{mg} / \mathrm{L}$ using biological treatment. The alkaline $\mathrm{pH}$ has been used to provide sweep coagulation mechanism and removing flocs in the biological reactor.

Findings of the current study, while being consistent with the similar studies, indicate that LAS removal by Fenton oxidation, as a second order reaction, has apparently high efficiency. However, the low COD removal efficiency corresponding to LAS indicates its incomplete decomposition. So that none of the 25 runs presented in Table 1, even including low initial LAS levels, acquired the allowable COD in the effluent. On this basis, it is necessary to identify LAS byproducts resulting from Fenton oxidation using special studies. It is obvious that the evaluation of LAS removal by Fenton oxidation will not be correct without attention to COD removal rates. Unfortunately, this issue has been overlooked in most studies.

\section{Conclusions}

Although Fenton oxidation appears as a high efficiency process in LAS removal, low efficiency of COD corresponding with LAS indicates its incomplete degradation by this process.

\section{Acknowledgments}

The authors would like to thank the research deputy of Urmia University of Medical Sciences (Iran) for financial supports. 


\section{References}

[1] Ivancovic T., Hrenovic J. // Arh Hig Rada Toksikol, 2010, 61, N 1. P. 95 - 110.

[2] Tadros T.H., Applied surfactants: principles and application - [1 $1^{\text {st }}$ Ed.]. Weinheim: Wiley-VCH Verlag GmbH \& Co. KGaA, 2005.

[3] Scott M.S., Jones M.N. // Biochem. et Biophysica Acta, 2000, 1508, N 1/2. P. $235-251$.

[4] Manousaki E., Psillakis E., Kalogerakis N., Mantzavinos D. // Water Res., 2004, 38, N 17. P. 3751 - 3759.

[5] Abdel-Rahman A.M., Mohamed A.A., M.Gad A.A., Hashem M. //J. Urban and Environ. Eng., 2013, 7, N 1. P. 34 - 142.

[6] Iranian Environment Protection Department. Environmental requlations and standard, the Iran Environment Protection Dept. Pub., Tehran, Iran, 2012.

[7] Mahvi A.H., Maleki A., Roshani B. // Pakistan. J. Biol. Sci., 2004, 7, N 12. P. $2222-2226$.

[8] Mousavi S.A.R., Mahvi A.H., Nasseri S., Ghafari Sh. // Iran. J. Environ. Health. Sci. Eng., 2011, 8, N 2. P. 129 - 138.

[9] Lin S.H., Lin C.M., Leu H.G. // Water Res, 1999, 33, N 7. P. 1735 - 1741.

[10] Mohd Ariffin A.H., Rozilawati Y., Siti Hajar A.M., // J. Chem. and Natural Resources Eng., 2007, N 2. P. 22 - 30.

[11] Wang X.J., Song Y., Mai J.S. // J. Hazard. Materials, 2008, 160, N 2/3. P. 344 348.

[12] Tsyntsarski R., Petrova B., Budinova T., Petrov N., Teodosiev D.K., Sarbu A., Sandu T., Yardim M.F., Sirkecioglu A. // Desalination and Water Treatment, 2013, N 1, P. $1-8$.

[13] Korzenowski C., Martins M.B.O., Bernardes A.M., Ferreira J.Z., Elizabeth C.N.F. Duarte, De Pinho M.N. // Ibid, 2012, N 44. P. 269 - 275.

[14] Kowalska I. // Ibid, 2013, N 51. P. 1366 - 1376.

[15] Munter R. // Proc. Estoninan Acad. Sci Chem., 2001, 50, N 2. P. 59 - 80.

[16] Soboleva N.M., Saprykina M.N., Kosinova V.N., Nosonovich A.A., Goncharuk V.V. // J. Water Chem. and Technol., 2012, 34, N 2. P. 96 - 102.

[17] Tchobanoglous G., Burton F.L., Stensel H.D. Wastewater engineering treatment and reuse $-\left[4^{\text {th }}\right.$ Ed.]. - New York: Metcalf and Eddy, McGraw-Hill, 2003. $745 \mathrm{p}$.

[18] Tanvanit P., Anotai J., Su C.C., Lu M.C. // Desalination and Water Treatment, 2013, N 51. P. $2820-2825$.

[19] Shvadchina Y.O., Vakulenko V.F., Levitskaya E.E., Goncharuk V.V. // J. Water Chem. and Technol., 2012, 34, N 5. P. 218 - 226. 
[20] Shvadchina Y.O., Vakulenko V.F., Sova A.N., Goncharuk V.V. // Ibid, 2013, 35, N 5. P. $195-202$.

[21] Khorsandi H., Bina B., Khorsandi J. // Polish J. Environ. Studies, 2015, 24, N 3. P. 1063 - 1068.

[22] Zarjam R., Mostafaei G., Akbari H., Atharizadeh M., Miranzadeh M.B. // J. Appl. Technol. in Environ. San., 2013, 3, issue 2. P. 101 - 110.

[23] APHA, $A W W A$ and $W E F$, Standard methods for the examination of water and wastewater - $\left[21^{\text {st }}\right.$ Ed]. - New York: American Public Health Association, 2005.

[24] Dolenko S.A., Alekseenko E.Y., Kushchevskaya N.F. // J. Water Chem. and Technol., 2011, 33, N 3. P. 183 - 186.

[25] Khorsandi H., Alizadeh R., Tosinejad H., Porghaffar H. // Water Sci. and Technol., 70, N 1. P. $95-101$.

[26] Khorsandi H., Movahedyan H., Bina B., Farrokhzadeh H. // Environ.Technol., 2011, 32, N 5. P. 499 - 506.

[27] Lee E., Lee H., Kim Y.K., Sohn K., Lee K. // Int. J. Environ. Sci. Technol., 2011, 8, N 2. P. $381-388$.

[28] Roy R.K. Design of experiments using the Taguchi approach: 16 steps to productand process. - New York: John Wiley and Sons Inc., 2001.

[29] Alok D.B., Wonyong C. // J. Hazard. Materials, 2014, 275. P. 121 - 135.

[30] Ahmadi M., Gorgani S. // Chem. and Materials Eng., 2014, 2, N 3. P. 87 - 91.

[31] Kestioglu K., Yonar T., Azbar N. // J. Process Biochem., 2005, N 7. P. 2416.

Received 13.01.2014 